\title{
Local Acquired Cyclosporiasis in an Immunocompromised Portuguese
} Boy

\author{
Vanessa Mendonça ${ }^{1 *}$, Teresa Carvalho ${ }^{2}$, Angélica Ramos ${ }^{2}$, Margarida Tavares ${ }^{3}$ and A Bonito Vitor ${ }^{4}$ \\ ${ }^{1}$ Serviço de Pediatria - Unidade Autónoma de Gestão da Mulher e da Criança do Hospital S. João do Porto, E.P.E, Portugal \\ ${ }^{2}$ Laboratório de Microbiologia do Serviço de Patologia Clínica - Unidade Autónoma de Gestão dos Meios Diagnósticos e Terapêutica do Hospital S. João do Porto, \\ E.P.E, Portugal \\ ${ }^{3}$ Unidade de Infecciologia Pediátrica do Serviço de Pediatria - Unidade Autónoma de Gestão da Mulher e da Criança do Hospital S. João do Porto, E.P.E, Portugal \\ ${ }^{4}$ Unidade de Imunoalergologia Pediátrica do Serviço de Pediatria - Unidade Autónoma de Gestão da Mulher e da Criança do Hospital S. João do Porto, E.P.E, Portugal
}

\begin{abstract}
Cyclospora cayetanensis is an emergent parasite traditionally associated with diarrhoea in travellers to endemic countries. Several cases of cyclosporiasis were also reported in non travellers associated with imported food and waterborne outbreaks. Recently, only sporadic cases were described in Europe, probably because it's underdiagnosed. Cyclospora is a protozoan very difficult to identify. It's not detected in specimen routinely tested for ova and parasite, if not explicitly requested. Other reasons include morphologic similarities of Cyclospora cayetanensis oocysts with those of Cryptosporidium; necessity of proficiency in parasitology and probably because its notification is not obligatory in all countries.
\end{abstract}

We report one case of acquired cyclosporiasis in Portugal in an immunocompromised boy, that is, to the best of our knowledge, the first reported in our country.

Cyclosporosiasis should be considered in all persons with persistent or remitting-relapsing diarrheal illness, regardless of immunological status and explicitly requesting testing for this parasite.

Keywords: Cyclospora cayetanensis; Cryptosporidium; Protozoan; Oocysts

\section{Introduction}

Coccidian are protozoan obligate intracellular parasites $[1,2,3]$, which include species that complete their life cycles in single hosts like Cyclospora, Eimeria, Isospora and Cryptosporidium and others that need intermediate hosts, like Toxoplasma, Neospora and Frenkelia $[2,4]$.

C. cayetanensis is an important and emerging cause of traveler's diarrhea and water and food-borne outbreaks associated with facilitated international travel and food importation from endemic areas [2,5]. In Europe, only a few cases have been described, and almost all of them were reported in patients returning from endemic countries $[2,6,7]$. In 2000, Peter C. Döller et al. [8] documented the first cyclosporiasis foodborne outbreak in Germany, with 34 persons related ingestion of a mixture of various types of baby lettuce leaves [8]. Luca Masucci et al. [9] reported the first documented case of acquired cyclosporiasis in Italy.

There is evidence that Cyclospora is transmitted by fecal-oral route $[1,4,5]$, but person-to-person transmission is unlikely because oocytes require days to weeks, depending on favorable climatic factors, to become infectious (sporulated oocysts) after leaving an infected host $[4,5,10]$. Cyclospora is also highly resistant to desiccation, common water and food disinfectants [5]. Indirect transmission is possible with sufficiently aged stools or stool contaminated products [4].

Humans appear to be the only host [2,11], but the role of animals as natural reservoirs is of increasing concern [6]. Recently, Cyclospora was identified in one chicken, two dogs and one monkey by microscopy and polymerase chain reaction [12]. Whether these findings represent a natural infection or either the shedding of ingested oocysts remains to be proven [2]. Mark Eberhard Nadeem Sajjad Raja and S. Schelenz reported a case of Cyclospora infection in a farm worker with close association with pigs' dysentery, although animal feces weren't tested [13]. In endemic areas, risk factors include contaminated water or food, contact with soil and domestic animals and poor sanitation [11].
AIDS epidemics in the 1980s enhanced the use of acid-fast stains to search opportunistic Cryptosporidium infections which in turn allowed observation of Cyclospora oocysts [5]. These were initially misdiagnosed as Cryptosporidium or assumed as an artefact and only in 1993 were classified as coccidian by Ortega and colleagues [14].

Cyclospora infection is diagnosed by examination of stool specimens using microscopy, sporulation studies or molecular diagnostic methods [5]. Diagnosis is challenging and difficult for several reasons: intermittent and low level of oocyst shedding [15]; morphological similarities between Cyclospora and Cryptosporidium oocysts, (Cyclospora oocysts are larger round organisms, with 8 to 10 $\mu \mathrm{m}$ of diameter) which manifestations are clinically indistinguishable; routine parasitology stains do not reliably demonstrate Cyclospora oocysts. Centers for Disease Control and Prevention recommend testing at least 3 samples that should be concentrated prior to microscopic examination to maximize recovery of oocysts [16]. Also, examination of wet mounts can be enhanced by: ultraviolet light fluorescence microscopy (Cyclospora oocyst wall auto-fluoresces, but not those of Cryptosporidium) and two special stains. With modified acid-fast stain (or Modified Kinyoun stain) - Cyclospora oocysts stain variably, ranging from no staining to deep purple and have a wrinkled appearance. Safranin stains oocysts uniformly, red to reddish-orange. This uniform staining decreases the risk of misdiagnosis that can result from modified acid-fast stain.

*Corresponding author: Vanessa Mendonça, Rua de Moçambique $n^{\circ} 467$ A, HAB 2N, 4100-349 Porto, Portugal, Tel: +351 9626530 76; E-mail: mendonca.vanessa@gmail.com

Received February 03, 2012; Accepted April 20, 2012; Published April 28, 2012

Citation: Mendonça V, Carvalho T, Ramos A, Tavares M, Vitor AB (2012) Local Acquired Cyclosporiasis in an Immunocompromised Portuguese Boy. J Clin Case Rep 2:135. doi:10.4172/2165-7920.1000135

Copyright: (c) 2012 Mendonça V, et al. This is an open-access article distributed under the terms of the Creative Commons Attribution License, which permits unrestricted use, distribution, and reproduction in any medium, provided the original author and source are credited. 
The clinical presentation varies with endemicity, with milder and shorter symptoms or even asymptomatic infections in endemic areas, because of repeated exposure. In non endemic areas infections are almost always symptomatic [5].

Clinical manifestations begin in average within 7 days after ingestion of sporulated oocysts and include watery diarrhea, anorexia, bloating, nausea, fatigue and low grade fever. Patients with primary immunodeficiency and other immunodepressed states like acquired immune deficiency syndrome are susceptible to foodborne infections $[17,18]$. Illness in these patients is more severe, protracted [2,3], relapsing and difficult to eradicate [17-19]. TrimethoprimSulfamethoxazole (TMP-SMX) is the treatment of choice $(5-25 \mathrm{mg} /$ $\mathrm{Kg}$ /day during 7 to 10 days, immunocompromised may need longer courses).

\section{Case Report}

A 15 year old boy, with mild primary combined immunodeficiency associated with short stature, hypothyroidism, chronic pulmonary infections and dermatophytosis, presented in March of 2011 with a history of chronic diarrhea. His symptoms included frequent watery stools, without blood or mucus, abdominal crumps, fatigue, anorexia and weight loss with 2 weeks of duration. He and his family live in an impoverished rural area, with poor hygiene conditions and no basic sanitation (have a septic tank). The patient usually has direct contact with soil and domestic animals (chickens, boar, and dog) and his family cultivate the vegetables they eat. He didn't have any travel history and all house hold members were free from such kind of symptoms. Also their animals didn't have diarrheal illness.

Patient observation revealed prostration with moderate dehydration, pallor and splenomegaly beyond his chronic dermatophytosis. Investigation revealed: microcytic hypochromic anemia (Hb: 10,5g/dL), no eosinophilia, leukocytosis or neutrophilia; negative acute phase reactants; liver, renal function tests and other biochemical profile were normal, except mild hypokalemia. A stool specimen obtained for testing for Cryptosporidium was observed in light microscopy with Modified Kinyoun stain and revealed oocysts with $8-10 \mu \mathrm{m}$, characteristic of Cyclospora cayetanensis (Figure 1)

Virologic and bacteriologic stool exams were negative. Abdominal ultrasound only showed homogeneous splenomegaly. Cytomegalovirus, Toxoplasma and Epstein Barr serologies were also negative. Their drinking water comes from spring water and its parasitological analysis was negative for Cyclospora spp. We also analysed boar faeces, which were negative for Coccidia.

He was treated with Trimethoprim-Sulfamethoxazole (TMPSMZ) $25 \mathrm{mg} / \mathrm{Kg} /$ day for 2 weeks with clinical improvement, but

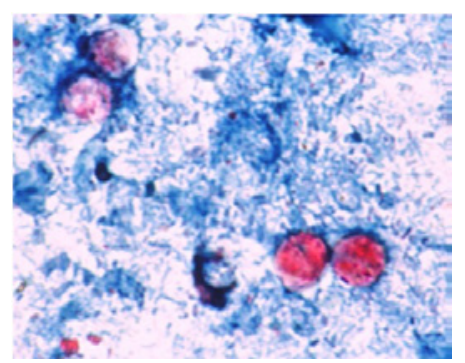

Figure 1: Cryptosporidium oocysts in light microscopy with Modified Kinyoun stain. relapsed symptoms within 2 months and it was done a second and longer (14 days) course with the same antibiotic. After completing this, he continued to excrete oocysts, which only stopped after 1 week of intravenous treatment with TMP-SMZ, when there was a remarkable clinical improvement.

\section{Discussion}

Cyclospora cayetanensis is an emergent parasite of public health concern. Despite some areas of the world are considered endemic [2,5], mostly developing countries, sporadic cases of cyclosporiasis in United States and Europe have been reported. Probably the prevalence of Cyclospora is underestimated in developed countries related to lack of expertise in the identification of this parasite in stools. Unless if specifically requested, in most of the laboratories, stool specimens examined for ova and parasites are not usually tested for Cyclospora. Identification of this protozoan requires special laboratory procedures that are not routinely done. Also, even with stains used to identify coccidian, like modified acid-fast stain, distinguish Cyclospora oocysts from those of Cryptosporidium may be challenging because of morphological similarities, which requires microscopy's expertise. Identification can still be missed due to intermittent shedding if insufficient samples tested.

Cyclospora is an important cause of prolonged diarrheal illness worldwide in immunocompetent and immunocompromised, is difficult to diagnose both clinically and with microscopy, and has specific antibiotic treatment; therefore, index of suspicion should be low to identify this agent.

With this in mind, probably in the future there will be more countries identified as endemic areas. Notification should be obligatory.

\section{References}

1. Belli SI, Smith NC, Ferguson DJ (2006) The coccidian oocyst: a tough nut to crack! Trends Parasitol 22: 416-423.

2. Chacín-Bonilla L (2010) Epidemiology of Cyclospora cayetanensis: A review focusing in endemic areas. Acta Trop 115: 181-193.

3. Robert M. Karanja, Wangeci Gatei, Njeri Wamae (2007) Cyclosporiasis: an emerging public health concern around the world and in Africa. African Health Sciences 7: 62-67.

4. Mansfielda LS, Gajadhar AA (2004) Cyclospora cayetanensis, a food- and waterborne coccidian parasite. Vet Parasitol 126: 73-90.

5. Ortega YR, Sanchez R (2010) Update on Cyclospora cayetanensis, a FoodBorne and Waterborne Parasite. Clin Microbiol Rev 23: 218-234.

6. Petry F, Hofstatter J, Schulz BK, Deitrich G, Jung M, et al. (1997) Cyclospora cayetanensis: first imported infections in Germany. Infection 25: 167-170.

7. P. Bourée , A. Lançon, G. Bonnot (2006) Une parasitose émergente : la cyclosporose: Revue à propos de 5 observations. An emerging parasitosis: cyclosporiasis. Antibiotiques 8: 73-78.

8. Döller PC, Dietrich K, Filipp N, Brockmann S, Dreweck C, Vonthein R, et al. (2002) Cyclosporiasis outbreak in Germany associated with the consumption of salad. Emerg Infect Dis 8: 992-994.

9. Masucci L, Graffeo R, Siciliano M, Franceschelli A, Bugli F, Fadda G (2008) First italian case of cyclosporiasis in an immunocompetent woman: local acquired infection. New Microbiol 31: 281-284.

10. RL Hall, Jones JL, Herwaldt BL (2011) Surveillance for Laboratory-Confirmed Sporadic Cases of Cyclosporiasis - United States, 1997-2008 Office of Surveillance, Epidemiology, and Laboratory Services, Centers for Disease Control and Prevention [CDC]. MMWR / 60: 1-11.

11. Chacín-Bonilla $L$ (2008) Transmission of Cyclospora cayetanensis infection: a review focusing on soil-borne cyclosporiasis. Trans R Soc Trop Med Hyg 102: 215-216.

12. Chu DM, Sherchand JB, Cross JH, Orlandi PA (2004) Detection of Cyclospora 
Citation: Mendonça V, Carvalho T, Ramos A, Tavares M, Vitor AB (2012) Local Acquired Cyclosporiasis in an Immunocompromised Portuguese Boy. J Clin Case Rep 2:135. doi:10.4172/2165-7920.1000135

cayetanensis in animal fecal isolates from Nepal using an FTA filter-base polymerase chain reaction method. Am J Trop Med Hyg 71: 373-379.

13. Sajjad Raja N, Schelenz S (2010) Cyclospora cayetanensis causing diarrhoea in adults in Norfolk, England: report of two cases and review of literature Scott Med J 55: 58.

14. Ortega YR, Sterling CR, Gilman RH, Cama VA, Diaz F (1993) Cyclospora Species -- A New Protozoan Pathogen of Humans. N Engl J Med 328: 13081312.

15. Cyclospora cayetanensis. Key points for laboratory diagnosis of cyclosporiasis

16. Centers for Disease Control and Prevention (CDC) Cyclosporiasis. Diagnostic findings.
17. Dropulic LK, Lederman HM (2009) Overview of infections in the immunocompromised host. In: Hayden RT, editor; Carroll KC, editor; Tang Y-W, editor; Wolk DM, editor. Diagnostic Microbiology of the Immunocompromised Host. Washington, DC: ASM Press. 3-43.

18. Sifuentes-Osornio J, Porras-Cortes G, Bendall RP, Morales-Villarreal F, Reyes-Teran G, et al. (1995) Cyclospora cayetanensis infection in patients with and without AIDS: biliary disease as another clinical manifestation. Clin Infect Dis 21: 1092-1097.

19. Stark D, Barratt JLN, Van Hal S, Marriott D, Harkness J, et al. (2009) Clinical significance of enteric protozoa in the immunosuppressed human population. Clin Microbiol Rev 22: 634-650. 